\title{
Systematic Construction of Xi'an Cultural Tourism Image*
}

\author{
Xiaoqing Zhu \\ School of Historical Culture and Tourism \\ Xi'an University \\ Xi'an, China 710065
}

\begin{abstract}
Xi'an is one of the earliest tourism cities. Tourism, especially the import one, has become the certificate of Xi'an. The requirements to the variety tourism and individual tourism are increased day by day with the economic and social development. Large tourism cities with rich tourism resources have entered the advanced stage of tourism development, but in terms of the development of Xi'an tourism, this phenomenon is not ideal. This phenomenon is inevitably caused by a variety of factors, including construction facilities, monuments and tourism cultural image. Finally, Xi'an has the reputation of "the old capital of China", and it is a city with rich cultural tourism resources. In order to promote the sustainable development of Xi'an's historical and cultural tourism, it is suggested to optimize the infrastructure, formulate the optimization scheme of Xi'an's urban image, provide technical support and improve the system of Xi'an's historical and cultural tourism, through which to hope to bring benefits to the development of Xi'an tourism.
\end{abstract}

Keywords-Xi'an City; historical culture and tourism; tourism image

\section{INTRODUCTION}

Since ancient times, human beings have engaged in tourism activities. With the progress of society, they have stepped into the modern tourism industry, and gradually formed a tourism industry with a huge system and deep influence. Tourism activities show unique brilliance in improving people's livelihood, economic quality and efficiency, building ecological civilization, and expanding friendly exchanges with foreign countries. It can be said that it has become a "Venus industry". The reform and opening up in 1979 opened a window of the world for China's tourism industry, which flourished thanks to the internal and external help. Tourism productivity has gradually become an important index to improve China's economic construction and industrial infrastructure structure optimization.

\section{A. Real Background of the Tourism Development of Xi'an}

From a regional perspective, in 2009, the "Guanzhong Economic Zone Development Plan" issued by the State

*Fund: The important social and science project for strategy cooperation between Xi'an Academy of Social Sciences and Xi'an University: The construction of system of cultural tourism image of Xi'an under the background of "One Belt and One Road"

Project number: 2019ZDZT17.
Council put forward efforts to build an international metropolis and a world-class tourist destination. The plan has changed the development goal of the city and raised higher requirements for the future development. The expansion of the website and the upgrading of the transport hub will provide a good foundation for the development and external conditions of the tourism industry.

From the perspective of domestic environment, in recent years, in order to speed up scientific development and promote development, the Municipal Council and the municipal government have identified five priorities for industrial development, including tourism, and strive to establish a city nature based on human resources and ecological resources by 2014 , The market also puts forward new requirements for "a new starting point for the construction of the Silk Road Economic Zone" and "a new harmonious and livable city", first of which is to build "five centers, one center and six centers". In the international metropolis with historical and cultural nature, a new situation is being created, including the construction of cultural tourism center. The implementation of many large-scale tourism projects contributes to the emergence and formation of new tourist attractions. The Xi'an Daming Palace Lounge, Cultural Exhibition Area on Taiwan Road, Ancient City Site of Chang'an in Han Dynasty, and Pengchuang National Tourist Resort all have become new tourism development departments. The urban pattern and tourism pattern of Xi'an are undergoing significant new changes.

The rapid social and economic development of Xi'an provides unprecedented opportunities and challenges for the development of tourism. Xi'an's tourism is one of the cities in the world with four special features. It is necessary to plan the future tourism development, strive to adapt to the requirements of international tourism competition, and actively participate in international tourism competition from a global perspective. In this way, Xi'an will become an important international tourism city and international tourism destination city in China's regional economic strategic layout.

\section{B. Purpose and Meaning of the Research}

At present, urban tourism is a new tourism mode, and the research about it is not very mature. Scholars and managers from all walks of life are studying it. In order to summarize the planning methods of urban tourism image, this paper 
will not change with some changes in the city. It has relative stability, such as "Spring City" and "Mountain City", "Spring Water City", "Ancient City", etc. These are cities with a certain history. It is not easy to change once formed.

\section{INFLUENTIAL FACTORS TO THE CONSTRUCTION OF TOURISM IMAGE OF XI'AN}

\section{FEATURE OF URBAN TOURISM IMAGE}

Therefore, the image of urban tourism is contemporary and cultural. Naturally, the same city has different images in different times and cultural backgrounds. Things are changing. The same is true of tourism image. Its internal characteristics are objectivity, subjectivity, relativity and stability.

\section{A. Objectivity}

People's impression is that the public has a specific understanding of all aspects of the city. It is a reflection of all aspects of the world in the eyes of the public. It's true. It can be generalized by specific expressions, such as words or images or ballads. Such as one hundred and five hundred miles, running within the sight, endless happiness; a windy city, silver, green, lake, jade, wind, flower, snow, moon, mountain, water, spring and stone; three mountains are taken as screens, being connected by one river; three rivers run through the city, the dragon pool reflects the thirteen peaks, with dragon hidden in the sky, flying dragon on the earth; the jade-like water crisscross the half lane, with the jet as the body, and the jasper as the spirit.

\section{B. Subjectivity}

As a comprehensive image, urban image is inevitably influenced by subjective factors, such as world view, opinions about value, thinking mode, norms, aesthetic orientation and gender differences. Therefore, everyone in the same city has their own views. The tourism form of a city is different from a city. In order to create a good image of city tourism in the public port, it is a must to attach importance to various activities in the construction of tourism image and to strive to educate publics. Therefore, before planning the image, first of all, it is necessary to understand the city's main source market and the positioning of the city's quality.

\section{Relativity}

The quality of urban tourism image is affected by the quality of a reference city and the subjective and objective factors, but the subjective and objective changes will also affect it. This correlation can be divided into vertical and horizontal. Compare with its own historical form vertically so as to shape the future image; compare with the image of other cities horizontally.

\section{Stability}

Urban tourism image is the result of city tourism comprehensive behavior. The formation of urban tourism destination, no matter its internal concept or external image, will form a bad center under certain space-time conditions. It
Xi'an is a famous historical and cultural tourism city with rich tourism resources. There are Big Wild Goose Pagoda, Small Wild Goose Pagoda, Ming City Wall, Yueqing Mosque, Banpo Remain, scenic area, Weiyang Scenic Area, Four major sites and other large-scale tourist areas and natural scenic areas with Zhou, Qin, Han and Tang cultural characteristics. Therefore, the elements of tourism image are various, which exist in all aspects of life. The following will

\section{A. Analysis of the Hardware System of Tourism Image of $X i$ 'an}

Hardware system is urban tourism and a tool of urban tourism. In a broad sense, all tangible entities related to tourism can be regarded as the hardware of tourism. Obviously, the factors include many buildings, urban parks, urban squares, urban tourism areas, urban roads, transportation, urban sculpture and urban ecology. The following is an analysis of the image of urban tourism from the perspective of the main influencing factors.

The revival plan of "ancient city" includes: Historical blocks protection and renewal plan of Three Learning Streets (academies), Huizu Settlement, Shuncheng Lane; protection of Square, Capital Town God's Temple, Xiangzi Temple, Guangren Temple, West Five etc.; restoration and environmental construction of Big Masjid, Temple, Forest of Stone Tablets, Dongyue Temple, Dongzi Temple, Eighth Route Army Office, official residence hall, park and ancient residence, etc.

In the historical district and urban environment, it is required to create a tourism environment full of history and culture. The historic environmental protection planning includes the ancient and modern buildings and blocks with the urban context, and gives new connotation to the new and historical environment.

The construction plan around the city includes: Protection and Restoration of Ming City wall (including connection, repair, restoration of city buildings and buildings behind the enemy), construction rounding the forest belt, city construction of the neighbor cities etc.; Treatment and development of wastewater interception by moat.

The urban planning and construction mainly includes: South Lake, Datang Night Market, Guangyuntan Wetland Park, Flashing Bridge Farewell-park, Silk-road Customs Park, Datang West City, Tang Daming Palace Heritage Park(Yudao road), Tang Changan City Remain Park (Jian), Yueyuanyuan Qinglong Temple etc.. Eight Immortals Palace, Zhouji Temple, Historical Museum, Zhangjiabao Sports Park and so on. analyze it from two aspects of hardware and software. 
The planning and construction of the tourist area within the scope of this city include Qinling Museum, Stone Museum, East Garden, Han Tomb, 1,000 mu forest land and Second Layer Heritage Park, Western Film City, Hot Spring Resort, Shuangyuan project, Louquan hot spring project, Longquan religious and cultural tourism development project, and Hanchi planning project.

It is necessary to attach importance to the investigation of cultural heritage, strengthen the protection and management of cultural heritage, and actively carry out the declaration of world heritage. In addition to the approved Terra Cotta Warriors, other cultural resources can also be declared as world material heritage, such as the ancient city wall of Xi'an (ancient architecture binding declaration), four sites of Xi'an (Daming Palace, Han Chang'an City, Afang Palace, and Pickaxe), etc., the starting point of the Silk Road, Forest of Stone Tablets in Xi'an, etc.

\section{B. Analysis of the Software System of Tourism Image of}

\section{$X i$ 'an}

Xi'an is a famous historical and cultural city with abundant tourism resources. It has not only rich historical and cultural resources, but also natural resources. Three thousand years of history has made it rich in culture, folk customs and historical sites. Eight hundred miles Qinchuan has brought up generations of people. At the same time, all people have maintained the continuity and prosperity of the three generations of Qin culture and made their due contributions to the preservation of historical treasures and traditional customs. Urban culture determines the local people's code of conduct, and their behavior affects the protection and development of tourism resources. Qi culture was deeply influenced by the culture of Qin, Han, Sui and Tang Dynasties. Xi'an is also a multi-ethnic city, and most of them are Han and Hui nationalities. It is also the birthplace and coexistence of Buddhism, Islam, Christianity and many religious schools. Xi'an also has its own custom, such as the house is half covered and the noodles are like trouser belts, the girl will not marry far away. There are many famous snacks with low price from the perspective of taste sense. There are gourd head, mutton mold, gourd chicken, cold rice noodle, toad, noodles, dumplings, cakes, persimmons, etc. Acoustically speaking, these are the auditory images of ancient music.

Tourism service and management are also part of urban tourism information system. Generally speaking, the level of tourism management is relatively low, especially the service level is low and the attitude is poor, which is the complaint of most tourists. $60 \%$ of tourists complain about the quality of tourism. The tourism service department thinks that the tourism service lacks quality and integrity, many service personnel lack training and understanding, some cultural units and tour guides cooperate with charities, which is not conducive to establishing a good image of Xi'an in the eyes of tourists.

\section{MEASURES OF TOURISM IMAGE CONSTRUCTION OF XI'AN}

\section{A. Taking Advantage of News Media}

In the information age, media is an indispensable part of people's life. It is a specialized agency for disseminating information and reporting news to the public. It usually covers four areas: media, television, radio, newspapers and magazines. Through the news media, the information dissemination of tourism cities can be expanded to the limit. The spread of information will be recognized and trusted by publics especially through the media with good reputation.

In the use of media, it is required to first select the media that are often used in the main source markets to publicize the image of urban tourism industry, and focus on the dissemination of information about the target tourism market. Each country has its own tourism market, which requires the analysis of cultural practices, economic conditions, customs and tourists' psychology in the main customer markets, and to strengthen the analysis of tourism market, especially the tourist market which needs scientific research. Choose the suitable media on the basis of investigation and analysis. It is very important to pay attention to the mass media while promoting the image of urban tourism. In the use of news media, attention should be paid to the design and development of image information that the publics like. It is necessary to do it from the perspective of tourists rather than from its own point of view in the process of making dissemination information, to try to make the information of tourism cities express itself in a way suitable for the tourism market and media, so that the information produced by this way can become as a useful tool to realize the dissemination of tourism city image.

There are many methods to disseminate the image of tourism city except for the traditional public media, such as exquisite travel manual, travelling in the tour city, participating the tourism exhibition and internet promotion activity etc.. Information and digital, especially the increase of internet and electric business, not only fundamentally change the economic growth mode but also change the city mode and life mode of China.

\section{B. Holding Festival Activity}

The success of the festival will have a huge impact on tourism cities. Many major cities in the world are celebrating the festival atmosphere, establishing friendly and extensive contacts, and inviting various guests and local citizens to participate in important festival activities. It is a strong proof that the Olympic Games not only provide great opportunities for urban tourism, but also for tourism industry. Moreover, the city image has been widely spread and made great contribution to the social and economic development of the city.

There are various forms of festival activities, such as major festivals, large-scale celebrations, Olympic Games, expositions, exhibitions and various opening ceremonies: folk art, religion, culture, singing and dancing, painting, film, sports, shopping, catering, etc. 


\section{REFERENCES}

\section{Carrying Out Public Relations Activities}

The public relations activities of a tourist city refer to the mutual understanding and trust between the tourist city and the external public, as well as the establishment of a good reputation and public image, which are conducive to the realization of the tourist objectives of the tourist city, including the development of public relations activities, tourism cities are mainly controlled by tourism departments of tourism cities, and their external audiences are mainly tourists, media, competitors and social organizations at home and abroad. Public relations activities play a role in collecting images of tourist cities, assisting in decisionmaking, communicating with the public at home and abroad, coordinating internal and external relations and the image of tourist cities.

\section{Renewal of Tourism Image of City}

1) Renewing the sale of tourism image of city: In the maintainance of the image of city tourism, it is also required to integrate image marketing to promote different types of tourism destinations. Hawaii, for example, a famous tourist attraction in the 20th century, is the first destination for its image. Different tourism markets can adopt different marketing combinations. For example, urban tourists can combine with typical urban tourism projects, while urban tourists can combine the natural attractions of the city.

2) Adopting subject technology extension: Theme promotion can be adopted in tourist cities. In fact, tourism cities have already built the theme of tourism cities, "shopping paradise", "charming capital" and "attractive capital" are all topics after introduction, which make people feel exciting and spread the overall image of China's tourism industry.

\section{CONCLUSION}

From the perspective of personal image, corporate image, industrial image, urban image and national image, this image has been extended to all areas of national life, and the research on it is also different. However, the actual theoretical and systematic research is neither comprehensive nor in-depth, especially the image of urban tourism, which is a new emerging field, and most of the research is relatively general, the image of urban tourism lags behind other image studies, and it has become the focus of people's attention, because the growth rate of urban tourism has been greatly accelerated. The image of urban tourism is the public's understanding and evaluation of the material and spiritual form of the inside and outside of the city.

As far as Xi'an is concerned, the theoretical system of establishing the city's tourism image was initially verified. The concept of Xi'an's tourism image is "the millennium of the ancient capital" in the world and "the cradle of the Chinese nation" in the whole country.
[1] Wang Weike. Development Review and Future Prospect of the World Tourism Industry [J]. Journal of Urumqi Vocational University, 2015 (in Chinese)

[2] Nan Yu, Yang Yongchun, Shi Ting. Analysis and Research on the Dynamic Evolution Structure of Inbound Tourist Market in Five Provinces of Northwest China [J]. Economic Geography, 2015 (in Chinese)

[3] Huang Cheng. New Research on the Construction of Tourism Infrastructure [J]. Heilongjiang Historical Annals, 2017. (in Chinese)

[4] Lu Dongji. Research on the Influence of Wuhan Guangzhou High Speed Railway on the Spatial Structure of Tourism in Wuhan [D]: Central China Normal University, 2016. (in Chinese)

[5] Xie Feifan. The Rise of Tourism Destination Image Research in This Paper [J]. Social Sciences, 2014. (in Chinese)

[6] Dou Zhiping. Research on the Construction of Urban Tourism Destination in Kunming [J]. Journal of Kunming Normal University, 2015. (in Chinese) 